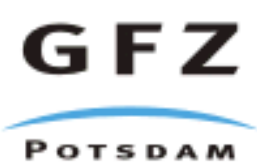

Originally published as:

Hennet, L., Pozdnyakova, I., Cristiglio, V., Cuello, G. J., Jahn, S., Krishnan, S., Saboungi, M.-L., Price, D. L. (2007): Short- and intermediate-range order in levitated liquid aluminates.

- Journal of Physics: Condensed Matter, 19, 455210

DOI: $10.1088 / 0953-8984 / 19 / 45 / 455210$ 


\title{
Short- and intermediate-range order in levitated liquid aluminates
}

\author{
L Hennet ${ }^{1}$, Pozdnyakova ${ }^{1}$, V Cristiglio ${ }^{1,2}$, G J Cuello ${ }^{2}$, S Jahn, ${ }^{3}$ S. \\ Krishnan, ${ }^{4}$ M.-L. Saboungi ${ }^{5}$ and D L Price ${ }^{1^{*}}$ \\ ${ }^{1}$ Centre de Recherche sur les Matériaux à Haute Température, 1d avenue de la \\ Recherche Scientifique, 45071 Orléans cedex 2, France \\ ${ }^{2}$ Institut Laue Langevin, 6 rue Jules Horowitz, BP48 Grenoble cedex 9, France \\ 3 GFZ, Telegrafenberg, 14473 Potsdam, Germany \\ ${ }^{4}$ KLA-Tencor, San José, CA 95134, USA \\ ${ }^{5}$ Centre de Recherche sur la Matière Divisée, $1 \mathrm{~b}$ rue de la Férollerie, 45071 Orléans \\ cedex 2, France \\ *Email: price@cnrs-orleans.fr
}

\begin{abstract}
We have used the aerodynamic levitation technique combined with $\mathrm{CO}_{2}$ laser heating to study the structures of liquid $\mathrm{CaAl}_{2} \mathrm{O}_{4}$ and $\mathrm{MgAl}_{2} \mathrm{O}_{4}$ with $\mathrm{x}$-ray and neutron diffraction. We determined the structure factors and corresponding pair correlation functions describing the short- and intermediate-range order in the liquids. The combination of the two scattering techniques makes it possible to derive information not accessible with a single measurement. In the case of the glass-forming liquid $\mathrm{CaAl}_{2} \mathrm{O}_{4}$ we have made sequential measurements during free cooling to study the structural evolution during supercooling from the stable liquid phase to the cold glass below $T_{g}$.
\end{abstract}

Keywords: Molten aluminates; $\mathrm{x}$-ray diffraction, ab initio simulations, liquid structure, aerodynamic levitation.

PACS numbers: 31.15.Ar; 33.15.Dj; 61.12.Ld; 61.20.Ja

\section{Introduction}

Most of the physical properties of a liquid are related to its atomic structure and dynamics [1]. It is therefore important to develop specific devices to probe the local environment of the atoms in the sample. At very high temperature it is difficult to use conventional furnaces, which present major problems. In particular, the sample can be polluted by the container and the structural properties of the materials can be affected by the crucible. This has led to the development of containerless techniques; we have chosen to work with the aerodynamic levitation method associated with $\mathrm{CO}_{2}$ laser heating [2].

The advantages are the simplicity and compactness of the levitation device, making it possible to integrate it easily in different beam lines at synchrotron and neutron sources. Over the past ten years, x-ray [3,4] and neutron scattering techniques [5] have been frequently used on levitated samples above the melting point and in the supercooled state and have provided structural information not previously available. More recently, the inelastic x-ray scattering technique has been applied to study the dynamics of high temperature levitated liquids [ 6]. In 
this paper, we present results on the structure of levitated liquid $\mathrm{CaAl}_{2} \mathrm{O}_{4}(\mathrm{CA})$ and $\mathrm{MgAl}_{2} \mathrm{O}_{4}$ (MA) obtained with $\mathrm{x}$-ray and neutron diffraction. As a baseline, we also review previous measurements on the end-member liquid $\mathrm{Al}_{2} \mathrm{O}_{3}$

\section{Technical details}

\subsection{Sample preparation}

$\mathrm{CaAl}_{2} \mathrm{O}_{4}$ and $\mathrm{MgAl}_{2} \mathrm{O}_{4}$ spherical samples were prepared by melting high-purity powders, previously pressed under an isostatic pressure of $200 \mathrm{MPa}$, in an aerodynamic levitator with a $\mathrm{CO}_{2}$ laser beam and then cooling to room temperature. They had a nominal diameter of $2.7 \mathrm{~mm}$, corresponding to weights of about $30 \mathrm{mg}$ (CA) and $40 \mathrm{mg}$ (MA).

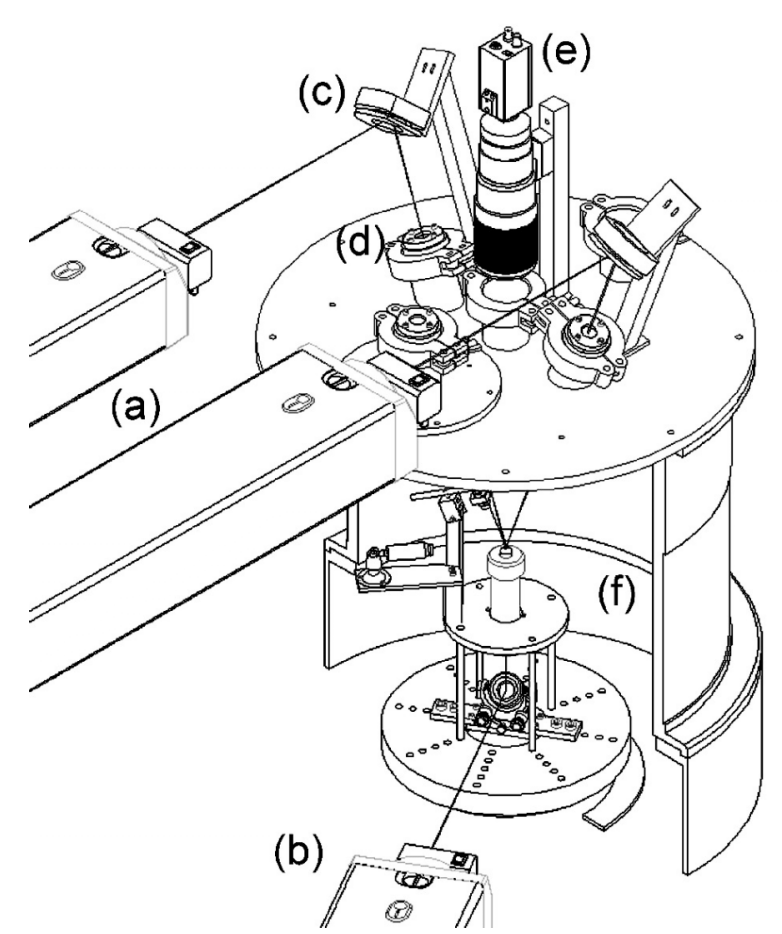

Figure 1. Schematic view of the experimental arrangement: laser heads (a,b), spherical mirrors (c), $\mathrm{NaCl}$ windows, (d) video camera (e), and levitation device (f).

\subsection{Aerodynamic levitation and heating system}

For these experiments, we used aerodynamic levitation combined with laser heating. Figure 1 shows a schematic view of the apparatus integrated into the D4c diffractometer at the Institut Laue-Langevin (ILL) in Grenoble (France) [5]. The aerodynamic levitation technique is described in detail elsewhere [2] and we give here a short description of the principle. A spherical sample (3 $\mathrm{mm}$ in diameter) is placed on a levitator that contains a convergentdivergent nozzle enabling the diffusion of a regulated gas flow onto the sample from below. This enables the sphere to remain in a stable position without any contact with the nozzle. When the sample levitates, it is heated by two $\mathrm{CO}_{2}$ lasers focused onto it by spherical mirrors from the top and from the bottom through the hole in the nozzle. The temperature is measured with one or two optical pyrometers. Several video cameras are used to monitor the sample during the heating process.

\subsection{X-ray and neutron diffraction 5}


The x-ray diffraction experiments on liquid $\mathrm{CaAl}_{2} \mathrm{O}_{4}$ were carried out at the $\mathrm{BM} 2$ beam line at the European Synchrotron Radiation Facility (ESRF) in Grenoble (France). We used the levitation chamber described in detail by Hennet et al. [2]. The scattered beam intensity was measured with a NaI-type scintillator scanned over a scattering angle range, $2 \theta$, of $5-120^{\circ}$, corresponding to a $Q$ range of $0.8-14.8 \AA^{-1}$. Subsequently, fast diffraction measurements were carried out with counting times of $100 \mathrm{~ms}$ at the 6.2 beam line [7] at the Synchrotron Radiation Source (SRS) at Daresbury (UK), using the $60^{\circ}$-aperture Rapid2 detector [8] developed at SRS. For both experiments we used monochromatic $\mathrm{x}$ rays with an energy of $16.9 \mathrm{keV}$, beam focusing optics and suitable slits to provide a focused $0.5 \times 1 \mathrm{~mm}$ rectangular beam at the sample.

X-ray diffraction measurements on liquid $\mathrm{MgAl}_{2} \mathrm{O}_{4}$ were carried out at the 12-1D-B beam line at the Advanced Photon Source in Argonne (IL, USA). For these experiments we used the levitation chamber described in Krishnan and Price [3]. In this case, the incident energy was 25 $\mathrm{keV}$ and the scattered beam was measured with a solid-state detector with $300 \mathrm{eV}$ resolution over a $2 \theta$ angular range of $5-85^{\circ}$, giving a maximum $Q$ value of $17.1 \AA^{-1}$.

Neutron scattering experiments on CA and MA were carried out at the D4c instrument at the Institut Laue-Langevin (ILL) in Grenoble (France). A precise description of this spectrometer can be found elsewhere [9] and the levitation setup is described in Hennet et al [5]. In this study we used a $\mathrm{Cu}[220]$ monochromator giving a working wavelength of $0.5 \AA$. The diffracted beam was measured over a $1.3-135^{\circ}$ angular range, corresponding to a $Q$ range of $0.3-23.2 \AA^{-1}$ with an average resolution $\Delta Q / Q=2.5 \times 10^{-2}$.

\section{Results and discussion}

\subsection{Structure of liquid $\mathrm{Al}_{2} \mathrm{O}_{3}$}

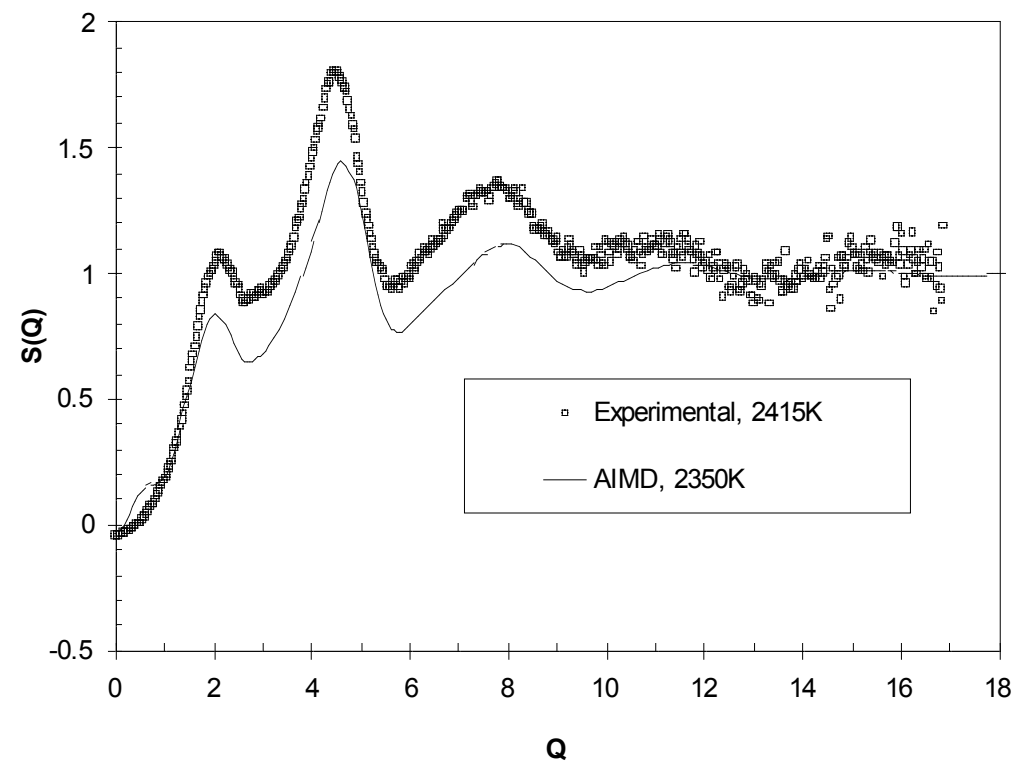

Figure 2. Comparison of the experimental $S(Q)$ for liquid $\mathrm{Al}_{2} \mathrm{O}_{3}$ obtained by x-ray diffraction with that obtained from the MD simulation with an ab initio interaction potential at a temperature of $2350 \mathrm{~K}$.

Before discussing the liquid aluminates, it is instructive to consider the results obtained on the pure end-member, liquid aluminium oxide. Figures 2 and 3 compare the results from a recent $x-$ ray diffraction (XRD) measurement and a molecular dynamics (MD) study [10] for the pair distribution function $G(r)$ and structure factor $S(Q)$, respectively. The MD simulations were performed using an advanced interatomic potential that accounts for instantaneous changes of 
the electronic structure of individual ions due to variations of their ionic environment [11]. Some small differences can be observed: the first peak is less well resolved from the second in the simulated $S(Q)$, and the shape of the second peak is more skewed to higher $Q$. In the comparison for $G(r)$, the first and second peaks agree quite well, while the third, originating from the Al-O second neighbours, is shifted to slightly smaller $r$ in the simulation.

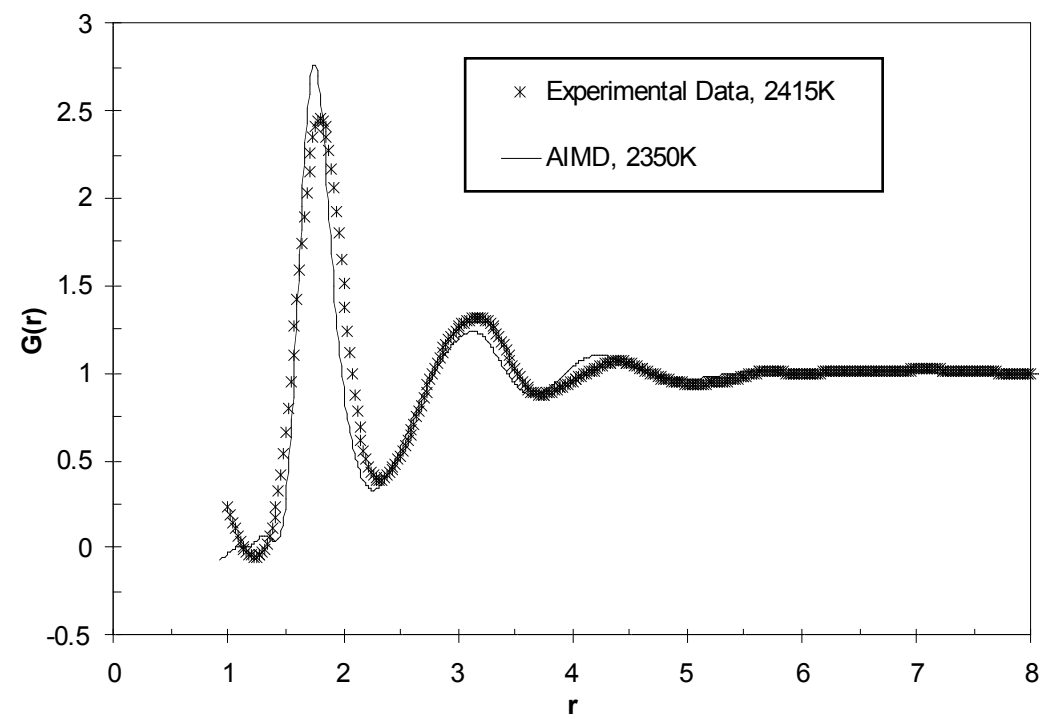

Figure 3. Comparison of the experimental $G(r)$ for liquid $\mathrm{Al}_{2} \mathrm{O}_{3}$ obtained by x-ray diffraction at $2415 \mathrm{~K}$ with that obtained from the MD simulation with an $a b$ initio interaction potential at a temperature of $2350 \mathrm{~K}$.

A point which should be borne in mind is that the x-ray weighted average $S(Q)$ is calculated from the MD partial structure factors on the basis of spherical ions centred at the nuclear sites with complete charge transfer, i.e., $\mathrm{Al}^{3+}$ and $\mathrm{O}^{2-}$, and this assumption is not necessarily correct. In an XRD study of liquid $\mathrm{FeCl}_{3}$, better agreement was found with less than complete charge transfer [12]. Part of the discrepancies mentioned could be due to this effect. Nevertheless, the overall agreement of the simulation with the present $\mathrm{x}$-ray data, as well as with previous neutron data [13] and inelastic x-ray scattering results [6], shows that the ab initio interaction potential provides a reliable basis for simulation molten salts, and extensions to more extreme states, nanoscale systems or longer time scales can be made with considerable confidence. Both the $\mathrm{XRD}$ and MD results give an average coordination number of about 4.5, made up predominantly of 4- and 5-fold coordinated $\mathrm{Al}$ ions, showing that $\mathrm{Al}_{2} \mathrm{O}_{3}$, unlike $\mathrm{Y}_{2} \mathrm{O}_{3}$ [4], undergoes an octahedral-tetrahedral transformation on melting.

These measurements were made in both reducing and oxidizing atmospheres, but the structural differences were much less pronounced than those observed in the optical absorption of $\sim 0.5$ $\mu \mathrm{m}$ radiation [14]. On the other hand the conductivity in the $\mathrm{MHz}$ regime measured with an electrodeless method combined with aerodynamic levitation does not show a significant difference either, while a significant decrease in the $\mathrm{MHz}$ conductivity, by about a factor five, was found in a strongly reducing $\mathrm{H}_{2}-\mathrm{Ar}$ environment [15]. It was unfortunately not possible to include such an environment in the x-ray study.

\subsection{Structure of liquid $\mathrm{CaAl}_{2} \mathrm{O}_{4}$}

Calcium aluminate binary compounds $\mathrm{CaO}-\mathrm{Al}_{2} \mathrm{O}_{3}$ can be vitrified to colourless transparent glasses in a narrow range of composition $(60-70 \mathrm{~mol} \% \mathrm{CaO})$ [16]. In addition to good 
mechanical properties [17], these glasses present some interesting optical characteristics, in particular high transparency in the mid-IR range up to $6 \mu \mathrm{m}$ [18]. In the past these glasses were considered for technological applications such as waveguides for infrared lasers [19]. However, they are relatively difficult to prepare because they have high melting points (about $1900 \mathrm{~K}$ ) and require rapid quenching. In addition, a tendency to devitrify easily limited their use as common optical materials [20]. Finally, the difficulty in making calcium aluminate glasses in large quantities has considerably reduced the interest in these compounds. A large part of these problems can be overcome by the addition of a small amount of $\mathrm{SiO}_{2}$ that extends the glassforming region and lowers the liquidus temperature [21]. However, the macroscopic properties are modified with the introduction of silica [22], suggesting structural modifications to these glasses. Before studying the influence of silica on the structure of calcium aluminates, it is necessary to have a reliable representation of the silica free structure. In this section, we present a structural study of the equimolar composition $\mathrm{CaAl}_{2} \mathrm{O}_{4}$ (CA) using $\mathrm{x}$-ray and neutron diffraction.

The melting temperature of $\mathrm{CA}$ is around $1878 \mathrm{~K}$ and in the liquid state some structural studies have been performed using NMR [23] and neutrons scattering [24]. Poe et al. [25] performed ion dynamics simulations and in situ ${ }^{27} \mathrm{Al}$ NMR spectroscopy to study the aluminium ion environment in glassy and liquid $\mathrm{CaO}-\mathrm{Al}_{2} \mathrm{O}_{3}$ compounds. The simulation results indicate that the average coordination number of $\mathrm{Al}$ is around 4.5 in the liquid state at the equimolar composition made up of 4-, 5- and 6-fold coordinated $\mathrm{Al}^{3+}$ ions.

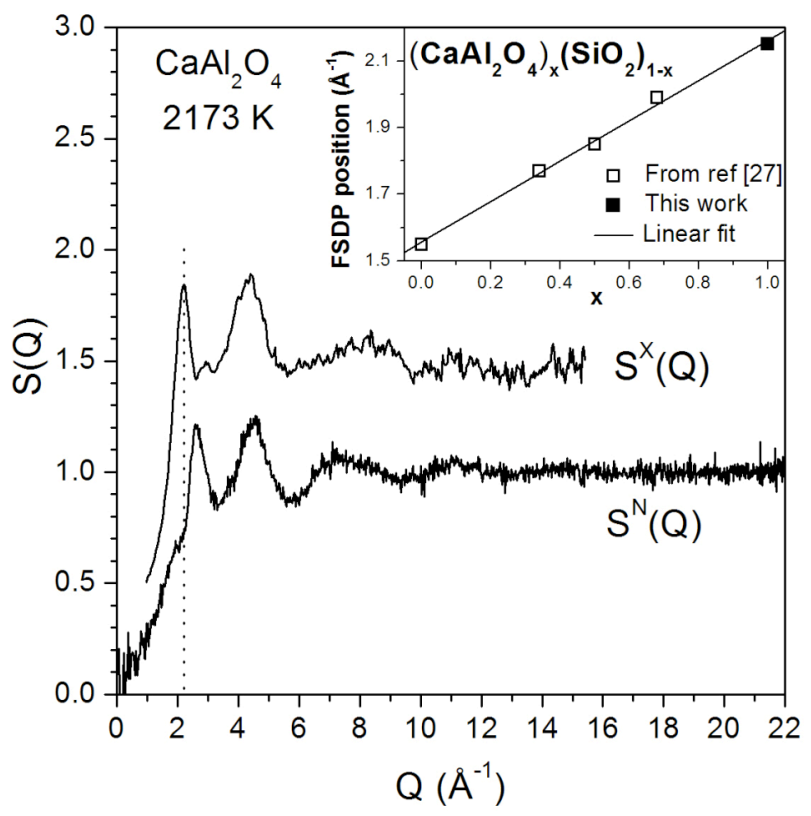

Figure 4. X-ray and neutron structure factors $S^{\mathrm{X}}(Q)$ and $S^{\mathrm{N}}(Q)$ for liquid $\mathrm{CaAl}_{2} \mathrm{O}_{4}$ at $2173 \mathrm{~K}$. The upper curve is shifted up by 0.5 for clarity. The inset shows the evolution of the FSDP position as a function of the composition $x$ in $\left(\mathrm{CaAl}_{2} \mathrm{O}_{4}\right)_{x}\left(\mathrm{SiO}_{2}\right)_{1-x}$ glasses.

Figure 4 shows the x-ray and neutron structure factors $S^{\mathrm{X}}(Q)$ and $S^{\mathrm{N}}(Q)$ for liquid CA at $2173 \mathrm{~K}$. Beyond $Q=4 \AA^{-1}$ the two curves are very similar, but in the low $Q$ region one can see that the first peak at $2.15 \pm 0.02 \AA^{-1}$ in $S^{\mathrm{X}}(Q)$ is much smaller in $S^{\mathrm{N}}(Q)$. If we consider the weights of the partial structure factors for $\mathrm{x}$-rays (at $\mathrm{Q}=2.15 \AA^{-1}$ ) and neutrons, the only way to explain this observation is to attribute this peak to cation-cation correlations as confirmed by preliminary molecular dynamics simulations. From these observations, a question arises: Does it 
correspond to the First Sharp Diffraction Peak (FSDP) related to the intermediate-range order (IRO) as observed in various liquids [26,27]. Although its position is at the upper limit for a FSDP and close to the main peak position in various liquids, it is not unusual to find FSDP at Q values above $2 \AA^{-1}\left(2.04 \AA^{-1}\right.$ in $\mathrm{SrSi}_{2} \mathrm{O}_{5}$ glass) [28].

In addition, several arguments point to this conclusion:

(i) The positions of the first peaks in $S(Q)$ can be used to classify the ordering in the liquid as proposed by Price et al. [27]. Taking $r_{l}=1.80 \AA$ (see further below), the first three peaks at $2.15,2.93$ and $4.38 \AA^{-1}$ give $Q r_{1}$ values of $3.87,5.27$ and 7.88 , which clearly correspond to IRO, CSRO (Chemical Short Range Order) and TSRO (Topological Short Range Order). Again, the value 3.87 is at the high end of values for FSDP but is not unreasonable.

(ii) Petkov et al. [29] studied calcium aluminosilicate glasses $\left(\mathrm{CaAl}_{2} \mathrm{O}_{4}\right)_{x}\left(\mathrm{SiO}_{2}\right)_{1-x}$ for $x$ in the 0-0.66 composition range. The structure factors for $\mathrm{x}>0$ are very similar to what we obtained with $\mathrm{CA}(\mathrm{x}=1)$. In particular all peaks beyond $2.93 \AA^{-1}$ in figure 1 are present and slightly shifted to high Q with increasing the $\mathrm{SiO}_{2}$ content while the FSDP is shifted to low $\mathrm{Q}$ values. The inset of figure 4 shows the evolution of the FSDP for $x$ in the $0-0.66$ composition range. The position obtained for CA $(x=1)$ is in good agreement with this evolution, showing a linear variation with the composition. In addition, it can be noticed that for these calcium aluminosilicate glasses the main peak is found at $Q$ values between 4 and $5 \AA^{-1}$ whatever the $\mathrm{x}$ value.

The following peak at $2.62 \pm 0.02 \AA^{-1}$ in $S^{\mathrm{N}}(Q)$, which does not appear in $S^{X}(Q)$, can be attributed to O-O correlations whose weighting factor is higher with neutrons. Further $\mathrm{X}$-ray absorption spectroscopy (XAS) and anomalous x-ray scattering measurements at the calcium absorption edge could give additional information on the local structure about $\mathrm{Ca}$ atoms.

Average pair correlation functions $g^{\mathrm{X}}(r)$ and $g^{\mathrm{N}}(r)$ were calculated using a number density $\rho_{0}=$ 0.074 atom $/ \AA^{3}$. The area under the first peak gives an $\mathrm{Al}^{3+}$ coordination number of $4.4 \pm 0.5$ in good agreement with the NMR [30] and neutron scattering [24] measurements. The second Gaussian gives a $\mathrm{Ca}-\mathrm{O}$ coordination number of $5.5 \pm 0.5$. There are no values in the literature for comparison from either x-ray or neutron scattering or NMR, where it is rather difficult to get this information due the low sensitivity of the ${ }^{43} \mathrm{Ca}$ isotope. On the other hand, the value we obtain for the liquid is similar to that given for the glass in Ref. [31], indicating that the $\mathrm{Ca}^{2+}$ coordination number does not change significantly between the liquid and the glass.

\subsection{Development of structural order on supercooling liquid $\mathrm{CaAl}_{2} \mathrm{O}_{4}$}

In order to study the evolution behavior of the structure during the cooling process, we performed measurements at intervals of $100 \mathrm{~ms}$ after turning off the laser power. Cooling was complete after about $6 \mathrm{~s}$ and cooling from the melting point temperature $T_{m}$ down to $T_{g}$ took about $2.7 \mathrm{~s}$, corresponding to a quench rate of $360 \mathrm{~K} / \mathrm{s}$. Thus, $100 \mathrm{~ms}$ measurements are fast enough to follow the structural evolution. Figure 5 shows the evolution of the width and height of the first peak of $S(Q)$ during the supercooling process. $T_{m}$ and $T_{g}$ are indicated by solid lines in Fig. 5; the value of $T_{m}$ was taken as $1878 \mathrm{~K}$ and $T_{g}$ from the last inflexion point common to the two curves: its value of $1173 \pm 30 \mathrm{~K}$ agrees with that $(1180 \pm 4 \mathrm{~K})$ obtained by DSC. Neither width nor intensity show any significant change down to a temperature of about $1467 \mathrm{~K}$ $\left(1.25 T_{g}\right)$, indicated by a dashed line in Fig, 5, after which the width decreases linearly down to $T_{g}$, where it stabilizes. The intensity starts to increase linearly at the same point and shows a lower slope after $T_{g}$. 
The Al-O coordination number, derived under the approximation that the $\mathrm{Ca}-\mathrm{O}$ coordination number is constant, is shown in Figure 6 along with the values of the position $r_{l}$ of the first peak. We find a coordination number of 4.4 in the liquid and around 4.0 in the glass. As observed for the $S(Q)$, changes occur after a temperature of $1467 \mathrm{~K}$ in the supercooled state, up to which the coordination number remains constant and after which it starts to decrease. The first peak position also starts to decrease at $1467 \mathrm{~K}$ down to a value of $1.76 \AA$ in the glass that agrees with previous structural studies [31,24]. This decrease in the first peak position is consistent with the decrease in coordination number since the presence of $\mathrm{AlO}_{5}$ and $\mathrm{AlO}_{6}$ in the liquid phase [23] increases the mean $\mathrm{Al}^{3+}$ ionic radii. The inflexion point of the curve is also consistent with the value of $1173 \pm 10 \mathrm{~K}$ for $T_{g}$ determined in Fig. 5.

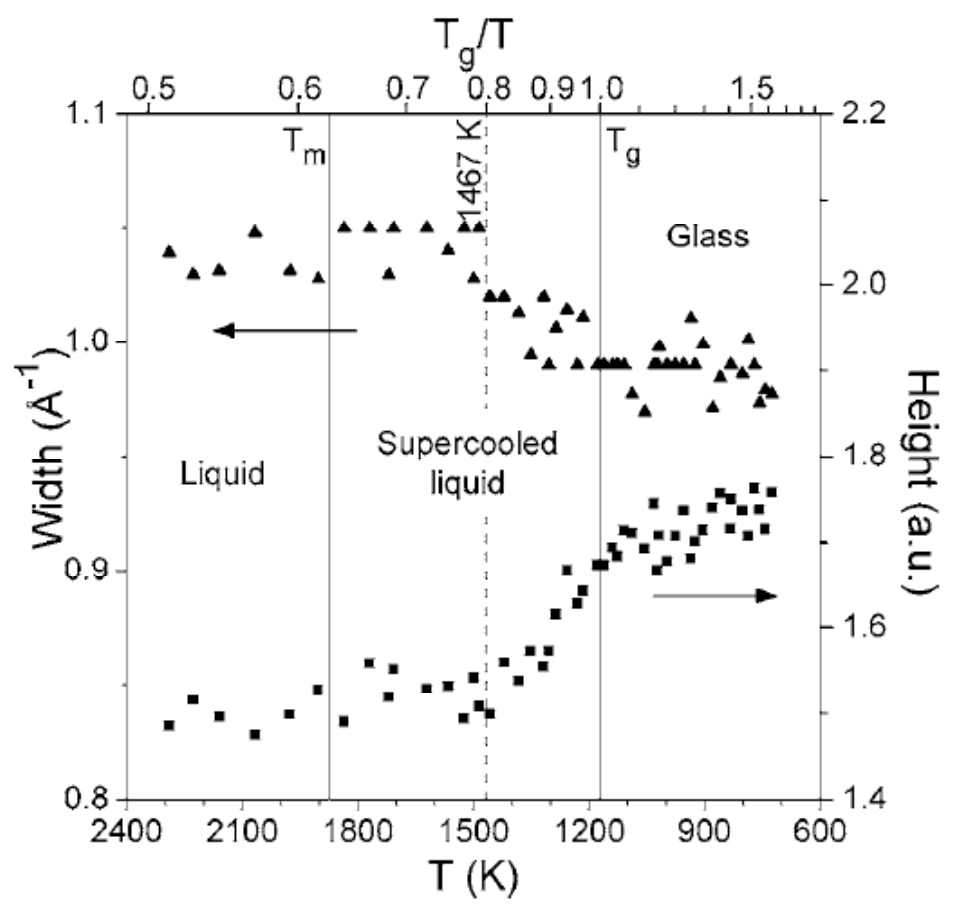

Figure 5. Dynamical evolution of the width and intensity of the first peak of $S(Q)$ during the cooling of liquid $\mathrm{CaAl}_{2} \mathrm{O}_{4}$ from $2173 \mathrm{~K}$ to room temperature. The melting $T_{m}$ and glass transition $T_{g}$ temperatures are shown by solid lines. The dashed line indicates the temperature $1467 \mathrm{~K}$ at which the structural evolution begins.

The onset of the increase in both intermediate-range and short-range order at $1.25 T_{g}$ is occurring close to the dynamic crossover where the slope of the Arrhenius plot increases, conventionally taken as $1.2 T_{g}$ for fragile liquids [32]. From a VTF (Vogel-Tammann-Fulcher) fit to the macroscopic viscosity data of liquid CA from Urbain 33, Poe et al. 34 determined a coefficient $\mathrm{D}=3.2$ characteristic of a very fragile liquid [35]. From this fit, it is possible to show that the change in viscosity becomes more pronounced around $1.2 T_{g}$. Twenty years ago, Angell pointed out the instability of intermediate-range order as a characteristic feature of fragile liquids [36]. In the energy landscape picture, the deeper minima assumed by the CA melt must correspond to an increase in structural order on both short and intermediate length scales. Furthermore, the cooling curve (evolution of the temperature vs. time, not shown) shows a kink at this temperature, indicating a change in thermodynamic properties consistent with the proposed connection between thermodynamic and kinetic fragility $[37,38]$. 


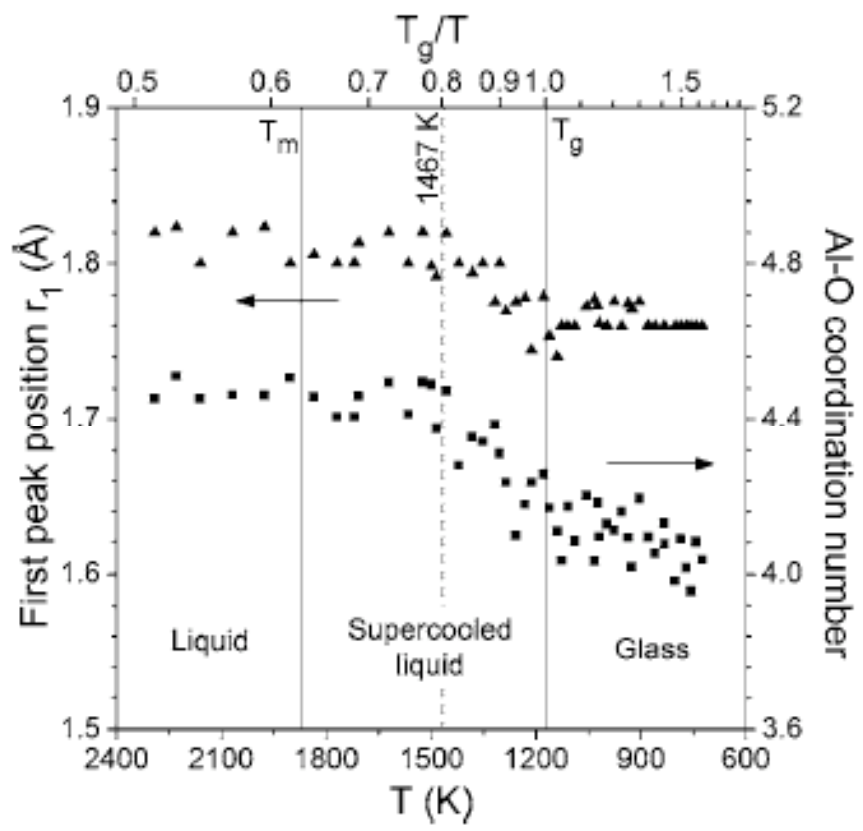

Figure 6. Dynamical evolution of the first peak position $r_{l}$ of the pair correlation function $T(r)$ and of the Al-O coordination number in liquid $\mathrm{CaAl}_{2} \mathrm{O}_{4}$. The melting $T_{m}$ and glass transition $T_{g}$ temperatures are shown by solid lines. The dashed line indicates the temperature $1467 \mathrm{~K}$ at which the structural evolution begins.

\subsection{Structure of liquid $\mathrm{MgAl}_{2} \mathrm{O}_{4}$}

$\mathrm{MgAl}_{2} \mathrm{O}_{4}$ (MA) is a refractory oxide with a melting point of $2408 \mathrm{~K}$. At room temperature, it exhibits a spinel cubic structure ( $\mathrm{Fd} 3 \mathrm{~m}$ space group). The $\mathrm{Al}$ sites are octahedral with an $\mathrm{Al}-\mathrm{O}$ distance of $1.91 \AA$ and $\mathrm{Mg}$ atoms are surrounded by 4 oxygen atoms with a bond length of 1.94

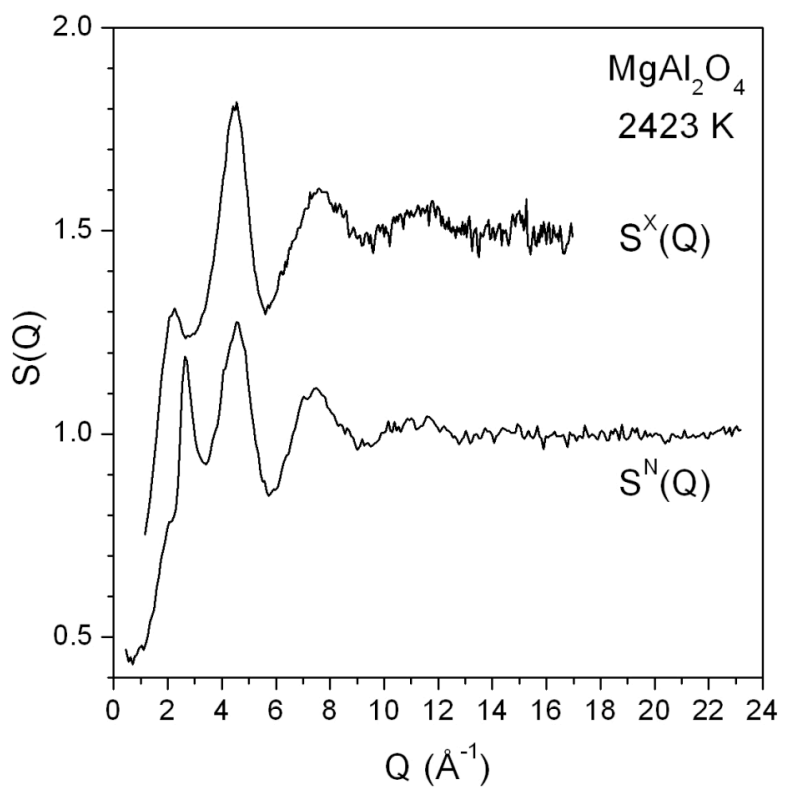

Figure 7. X-ray and neutron structure factors $S^{\mathrm{X}}(Q)$ and $S^{\mathrm{N}}(Q)$ for liquid $\mathrm{MgAl}_{2} \mathrm{O}_{4}$ at $2423 \mathrm{~K}$. The upper curve is shifted up by 0.5 for clarity. 
$\AA$. In the liquid state, the only reported work has been performed with ${ }^{27} \mathrm{Al}$ NMR spectroscopy [25] and thus is limited to a study of the aluminium ion environment. To our knowledge, there is no published work that uses x-ray or neutron diffraction. In this section, we present a structural study of the liquid spinel.

Figure 7 shows the x-ray and neutron structure factors $S^{\mathrm{X}}(Q)$ and $S^{\mathrm{N}}(Q)$ for liquid MA at 2423 K. As for $\mathrm{CaAl}_{2} \mathrm{O}_{4}$, the two curves are very similar beyond $Q=4 \AA^{-1}$. Based on the calculated weighting factors, the peak at $2.64 \pm 0.02 \AA^{-1}$ in $S^{\mathrm{N}}(Q)$, which is not visible in $S^{\mathrm{X}}(Q)$, can also be assigned to O-O correlations. In contrast to liquid CA, the first peak in $S^{\mathrm{X}}(Q)$ at $2.22 \pm 0.02 \AA^{-1}$ is much lower, but in $S^{\mathrm{N}}(Q)$ its intensity is higher than the first peak, which appears as a shoulder.

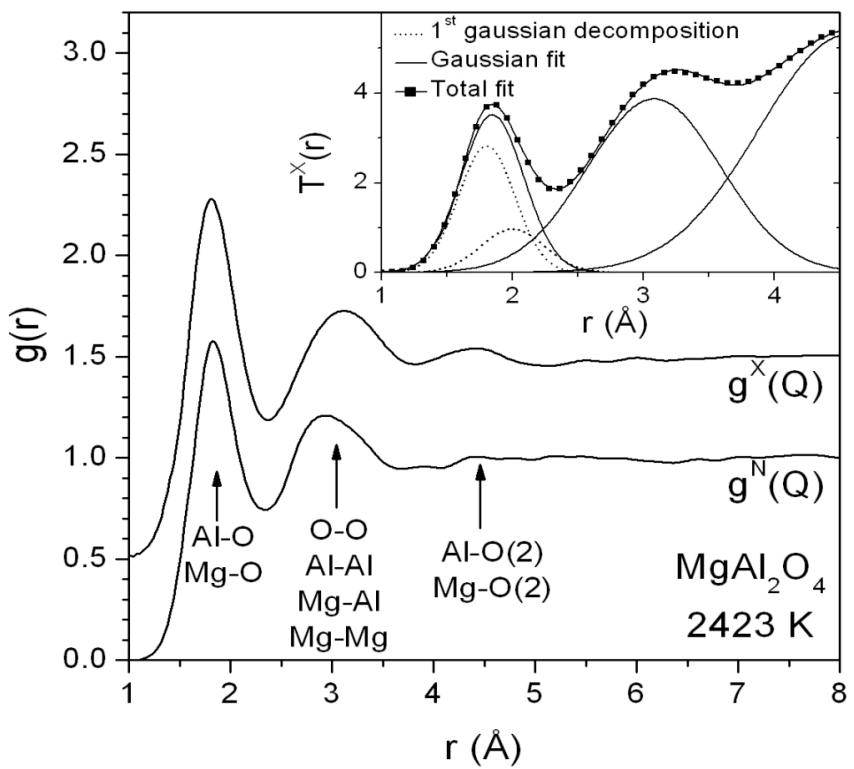

Figure 8. X-ray and neutron pair correlation functions $g^{\mathrm{X}}(r)$ and $g^{\mathrm{N}}(r)$ for liquid $\mathrm{MgAl}_{2} \mathrm{O}_{4}$ at $2423 \mathrm{~K}$. The upper curve is shifted up by 0.5 for clarity. The inset shows a Gaussian fit to the x-ray total correlation function $T^{\mathrm{X}}(Q)$. The fit to the first peak using two Gaussians is shown by the dashed lines.

Figure 8 shows the corresponding average pair correlation functions $g^{\mathrm{X}}(r)$ and $g^{\mathrm{N}}(r)$ calculated using a number density $\rho_{0}=0.081$ atom $/ \AA^{3}$. The x-ray pair correlation function exhibits three peaks between 1 and $5 \AA$. By comparison with the structure of liquid $\mathrm{Al}_{2} \mathrm{O}_{3}$ [10], we can propose a peak assignment. The first peak at $1.81 \pm 0.03 \AA$ is due to $\mathrm{Al}-\mathrm{O}$ and $\mathrm{Mg}-\mathrm{O}$ correlations, the second peak at $3.11 \pm 0.04 \AA$ is a combination of all other pairs including O-O, $\mathrm{Al}-\mathrm{Al}, \mathrm{Mg}-\mathrm{Al}$ and $\mathrm{Mg}-\mathrm{Mg}$ and the third peak at $4.42 \pm 0.06 \AA$ arises from the next nearest neighbour $\mathrm{Al}-\mathrm{O}$ and $\mathrm{Mg}-\mathrm{O}$ correlations. The first two peaks in $g^{\mathrm{N}}(r)$ are found at $1.83 \pm 0.02 \AA$ and $2.93 \pm 0.03 \AA$. While the first position is in good agreement with x-rays, the second peak occurs at a lower $r$ and has a shoulder on the high- $r$ side. With neutrons, the second peak is mostly due to O-O correlations and thus shifted towards the O-O bond distance, while the shoulder is due to the cation-cation correlations.

From Gaussian fits to $T^{\mathrm{x}}(Q)$ and $T^{\mathrm{N}}(Q)$ (the inset to figure 8 shows the fit to the $\mathrm{x}$-ray total correlation function), we obtained $\mathrm{Al}-\mathrm{O}$ and $\mathrm{Mg}-\mathrm{O}$ coordination numbers of $4.3 \pm 0.5$ and $5 \pm$ 0.5 . The Al-O coordination number is in good agreement with the NMR work [22] where a value of 4.67 was determined. Using these results we modelled the first peak with two Gaussians with fixed areas corresponding to the calculated coordination numbers. The result is 
shown in the inset to figure 4 for $\mathrm{x}$-rays. In this case, the first peak is found at $1.78 \pm 0.05 \AA$ and the second at $1.96 \pm 0.05 \AA$, corresponding to $\mathrm{Al}-\mathrm{O}$ and $\mathrm{Mg}-\mathrm{O}$ correlations respectively. With neutrons, we found distances of $1.76 \pm 0.05 \AA$ and $1.93 \pm 0.05 \AA$. The interpretation of the other peaks is more difficult due to the combination of various correlations in $g(r)$.

Molecular dynamics simulations with the procedure described above [11] gives distances $r_{\mathrm{Al}-\mathrm{O}}=$ $1.76 \AA$ and $r_{\mathrm{Mg}-\mathrm{O}}=2.03 \AA$, and coordination numbers $\mathrm{Al}(\mathrm{O})=4.3$ and $\mathrm{Mg}(\mathrm{O})=5.1$. As in pure $\mathrm{Al}_{2} \mathrm{O}_{3}$, the $\mathrm{Al}$ ions are 4- and 5-fold coordinated and the $\mathrm{Mg}$ ions predominately 5-fold coordinated with an admixture of 4- and 6-fold, corresponding to extremely distorted tetrahedra and octahedra.

\section{Conclusions}

The use of aerodynamic levitation combined with laser heating presents a relatively simple and versatile approach for studying high-temperature molten aluminates and other oxides with a variety of techniques, including x-ray and neutron diffraction, inelastic x-ray scattering, and electrodeless measurements of conductivity and other physical properties. With rapid counting rates made possible by area detectors at synchrotron sources, it is possible to study structural changes in real time during cooling toward and through the glass and freezing transitions.

In this work we have presented results for short-range order derived from the pair distribution functions measured for liquid equimolar calcium and magnesium aluminates. By combining $\mathrm{x}-$ ray and neutron diffraction with MD computer simulations we have established that in these binary liquids, as in pure liquid alumina, the $\mathrm{Al}^{3+}$ ions adopt a predominantly tetrahedral coordination while the $\mathrm{Ca}^{2+}$ and $\mathrm{Mg}^{2+}$ ions occupy a mixture of 4-, 5- and 6-fold coordinated sites, corresponding to highly distorted tetrahedra and octahedra. We also obtain information on the intermediate-range order from the low- $Q$ region of the structure factor. The liquid aluminates are fragile liquids, and measurements on the equimolar calcia-alumina system on supercooling towards the glass transition reveal an increase in both intermediate-range and short-range order at a temperature close to the dynamic crossover where the slope of the Arrhenius plot of the viscosity increases.

\section{Acknowledgements}

The authors wish to thank the APS, ESRF, SRS and ILL staff for their help with the experiments. Helpful discussions with C. A. Angell during the entire course of this work are gratefully acknowledged. This work was partially supported by the CNRS and the Regional Council of the Région Centre. The APS is supported by the U.S. Department of Energy, Office of Science, Office of Basic Energy Sciences, under Contract No. W-31-109-ENG-38.

\section{References}

1 D. L. Price, M.-L. Saboung, F. J. Bermejo, Rep. Prog. Phys. 66 (2003) 407

2 L. Hennet, D. Thiaudière, M. Gailhanou, C. Landron, J. P. Coutures, D. L. Price, Rev. Sci. Instrum. 73 (2002) 124

3 S. Krishnan, D.L. Price, J. Phys.: Condens. Matter, 12 (2000) R145

4 L. Hennet, D. Thiaudière, C. Landron, P. Melin, D. L. Price, J.-F. Bérar, J.-P. Coutures, M.-L. Saboungi, Appl. Phys. Lett. 83 (2003) 3305

5 L. Hennet, I. Pozdnyakova, A. Bytchkov, V. Cristiglio, P. Palleau, H. Fischer, G. J. Cuello, M. Johnson, P. Melin, D. Zanghi, S. Brassamin , J.-F. Brun D. L. Price, M.-L. Saboungi, Rev. Sci. Instr. 77 (2006) 053903

6 H. Sinn, B. Glorieux, L. Hennet, A. Alatas, M. Hu, E.E. Alp, F.J. Bermejo, D. L. Price, M.L. Saboungi, Science 299 (2003) 2047 
7 C. C. Tang, C. M. Martin, D. Laundy, S. P. Thompson, G. P. Diakun, R. J. Cernik, Nucl. Instrum. Methods Phys. Res. B222 (2004) 659

8 A. Berry, W. I. Helsby, B. T. Parker, C. J. Hall, P. A. Buksh, A. Hill, N. Clague, M. Hillon, G. Corbett, P. Clifford, A. Tidbury, R. A. Lewis, B. J. Cernik, P. Barnes, G. E. Derbyshire, Nucl. Instrum. Methods Phys. Res. A 513 (2003), 260

9 H. E. Fischer, G. J. Cuello, P. Palleau, D. Feltin, A. C. Barnes, Y. S. Badyal, J. M. Simonson, Appl.

Phys. A 74 (2002) S160

10 S. Krishnan, L. Hennet, S. Jahn, T. A. Key, P. A. Madden, M.-L. Saboungi, D. L. Price, Chem. Mater. 17 (2005) 2662

11 S. Jahn, P. A. Madden, J. Non-Cryst. Solids (in press).

12 Y. S. Badyal, M.-L. Saboungi, D. L. Price, D. R. Haeffner, S. D. Shastri, Europhys. Lett. 39, (1997) 19

13 C. Landron, L. Hennet, T. E. Jenkins, G. N. Greaves, J. P. Coutures, A. K. Soper, Phys. Rev. Lett. 86 (2001) 4839

14 J. K. R. Weber, S. Krishnan, C. D. Anderson, P. C. Nordine, J. Amer. Ceram. Soc. 78 (1995) 583; J.

K. R. Weber, P. C. Nordine, S. Krishnan, ibid., 3067.

15 B. Glorieux, M-L Saboungi, J. Enderby, Europhys. Lett. 56 (2001) 81

16 J. E. Shelby, C. M. Shaw, M. S. Spess, J. Appl. Phys., 66 (1989) 1149

17 F.T. Wallenberger, S.D. Brown, Comp. Sci. Technol. 51 (1994) 243

18 L-G Hwa, C-C Chen, S-L Hwang, Chinese J. Phys., 35 (1997) 78

19 T. Abel, J. A. Harrington, P. R. Foy, Applied Optics, 33 (1994) 3919

20 M.E. Lines, J.B. MacChesney, K.B. Lyons, A.J. Bruce, A.E. Miller, K. Nassau. J. Non-Cryst. Solids 10 (1989) 251

21 J.E. Shelby. J. Am. Ceram. Soc. 68 (1985) 155

22 P.L. Higby, R.J. Ginther, I.D. Aggarwal, E.J. Friebele. J. Non-Cryst. Solids 126 (1990) 209

23 B.T. Poe, P.F. McMillan, B. Coté, D. Massiot , J.P. Coutures, Science 259 (1993) 768

24 J. K. R. Weber, C. J. Benmore, J. A. Tangeman, J. Siewenie, K. J. Hiera, J. Neut Research 11 (2003) 113

25 B.T. Poe, P.F. McMillan, B. Coté, D. Massiot, J.P. Coutures, J. Am. Ceram. Soc. 77 (1994) 1832

26 S. C. Moss, D. L. Price, Physics of Disordered Materials, edited by D. Adler, H. Fritzsche, S. R.

Ovshinsky (Plenum, NY, 1985), p. 77.

27 D. L. Price, S. C. Moss, R. Reijers, M.-L. Saboungi, S. Susman, J. Phys: Condens. Matter 1 (1989)

1005

28 P. H. Gaskell, D. J. Wallis, Phys. Rev. Lett. 76 (1996), 66

29 V. Petkov, Th. Gerber, B. Himmel et al., Phys. Rev. B 58 (1998) 11982

30 D. Massiot, D. Trumeau, B. Touzo, I. Farnan, J. C. Rifflet, A. Douy, J. P. Coutures, J. Phys. Chem. 99 (1995) 16455

31 C. J. Benmore, J. K. R. Weber, S. Sampath, J. Siewenie, J. Urquidi, J. A. Tangeman, J. Phys. Cond. Mat. 15 (2003) S2416

32 C. A. Angell, J. Non-Cryst. Solids 73 (1985) 1

33 G. Urbain, Rev. Int. Hautes Tempér. Refract. Fr. 20 (1983) 135

34 B.T. Poe, P.F. McMillan, B. Coté, D. Massiot, J. P. Coutures, J. Am. Ceram. Soc. 77 (1994) 1832

35 R. Bohmer, C. A. Angell, Phys. Rev. B 45 (1992) 10091

36 C. A. Angell, J. Non-Cryst. Solids 73 (1985) 1

37 K. Ito, C. T. Moynihan, C. A. Angell, Nature 398 (1999) 492

38 L.-M. Martinez, C. A. Angell, Nature 410 (2001) 663 